\title{
Child-Pugh Class C12
}

National Cancer Institute

\section{Source}

National Cancer Institute. Child-Pugh Class C12. NCI Thesaurus. Code C146797.

A total score of 12 for hepatic function, corresponding to class C in the Child-Pugh classification. 